\title{
Exploring Some Aspects Associated with Dentine Hypersensitivity in Children
}

\author{
Caleb Shitsuka, ${ }^{1}$ Fausto Medeiros Mendes, ${ }^{1}$ \\ Maria Salete Nahás Pires Corrêa, ${ }^{1}$ and Mariana Ferreira Leite ${ }^{2}$ \\ ${ }^{1}$ University of São Paulo, São Paulo, SP, Brazil \\ ${ }^{2}$ University of Cruzeiro do Sul, São Paulo, SP, Brazil \\ Correspondence should be addressed to Caleb Shitsuka; caleb@usp.br
}

Received 30 September 2014; Revised 5 March 2015; Accepted 5 March 2015

Academic Editor: Cornelis H. Pameijer

Copyright (C) 2015 Caleb Shitsuka et al. This is an open access article distributed under the Creative Commons Attribution License, which permits unrestricted use, distribution, and reproduction in any medium, provided the original work is properly cited.

Background. The etiology of dentine hypersensitivity (DH) is still inconclusive and there are few studies concerning it in children. Aim. To evaluate clinical, dietary, and salivary variables in children with DH complaints. Design. Forty-eight children were asked about DH. Data regarding dietary habits were collected from the children's parents and an examination was performed to determine dental erosion. Dental biofilm was estimated by oral hygiene status, according to Greene and Vermillion's Simplified Oral Hygiene Index (OHI-S). Whole saliva was collected under mechanical stimulation and evaluated salivary flow rate, initial pH, buffer capacity, and calcium and phosphate concentrations. The temperature of soft drinks, drinking method, sense of bitter taste, and other variables were also determined. Possible factors associated with $\mathrm{DH}$ were analyzed by univariate and multiple Poisson regression analyses. The prevalence ratio (PR) values and 95\% confidence intervals (95\% CI) were calculated. Results. DH was associated with the presence of dental erosion ( $\mathrm{PR} ; 95 \% \mathrm{CI}=2.23 ; 1.05$ to 4.71 ) and salivary flow rate $(2.49 ; 1.05$ to 5.91$)$. When the presence of erosion was not included, other variables were retained as follows: bitter taste (2.36; 1.38 to 4.03$)$, OHI-S (0.47; 0.23 to 0.97$)$. Conclusion. $\mathrm{DH}$ in children is associated with factors related to dental erosion.

\section{Introduction}

Dentine hypersensitivity (DH) is one of the most frequent complaints in the dental office related to loss of tooth structure [1-3]. It is characterized by acute pain of sudden onset and short duration that is typically caused by thermal, evaporative, tactile, osmotic, or chemical stimulation of open dentine tubules and exposed surface and cannot be ascribed to any other form of defect or pathology [4]. The "hydrodynamic theory" proposed by Brännström et al. [5] is widely used to explain the mechanism of action of DH; however, its etiologic factors and diagnosis remain inconclusive [6].

The prevalence for HD is not well understood; however, some studies indicate that about $30 \%$ of the general population report HD [7-9]. Some of the main etiological factors of $\mathrm{DH}$ are chronic trauma from toothbrushing, acid erosion (e.g., as a result of environmental exposure, gastric regurgitation, or dietary substances), and anatomical factors [10].
Saliva plays a key role in maintaining the mineralized structure of the tooth due to its participation in the pellicle formation, buffer capacity, and supersaturation of electrolytes [11]. However, the association of salivary parameters with DH has not been extensively studied. Furthermore, since protection of the tooth surface is of fundamental importance in the prevention and treatment of $\mathrm{DH}$, we believe it is of interest to study the role of dental biofilm in individuals who present this symptom. Despite the possibility of aciduric microorganism colonization, under healthy conditions, dental biofilm has a protective function in relation to the enamel surface, acting as selective barrier against acid penetration and as a reserve of ions, such as calcium fluoride [12]. A negative correlation between plaque accumulation and the presence of $\mathrm{DH}$ has been demonstrated, suggesting that dental biofilm could be a protective factor for the dental surface [13]. However, few studies address this possible association between the presence of biofilm and the reduction in $\mathrm{DH}$ [14]. 
Although several studies related to the prevalence, etiology, and treatment of $\mathrm{DH}$ have been published, most of them have focused on its occurrence in adolescents and adults. In children, $\mathrm{DH}$ has been related to dental developmental defects, such as amelogenesis imperfecta [15] and hypomineralization [16]. There is a lack of studies concerning DH in children with no developmental dental defects. Thus, the aim of this study was to evaluate clinical and salivary aspects associated with $\mathrm{DH}$ in children. This is the first study that investigated associated clinical and salivary factors with $\mathrm{DH}$ in children.

\section{Material and Methods}

2.1. Subjects. This cross-sectional study was approved by the Human Research Ethics Committee of the Cruzeiro do Sul University under protocol number 015/2010. After being informed of the purpose of the investigation, written informed consent for participation and publication was obtained from the adult responsible for each child who agreed to participate in this study.

A group of 48 male and female children (aged 4-9 years old) attending the Clinic of Pediatric Dentistry of Cruzeiro do Sul University was enrolled in this study. A convenience selection procedure was performed according to the presence of dental erosion. Children were initially selected according to the presence of dental erosion, after which control children with no dental erosion were selected and paired for age and sex. Additional inclusion criteria were children with no caries or with absence of systemic disease. Children exhibiting incipient caries, failed restorations, cracks or dental fractures, and teeth with reversible or irreversible inflammatory processes of the pulp were excluded.

2.2. Collection of the Independent Variables. The patients were examined according to dental erosion criteria and oral hygiene status by a single examiner in a dental chair condition for a good evaluation.

Oral hygiene was assessed according to Greene and Vermillion's Simplified Oral Hygiene Index (OHI-S) [17]. The dental surfaces were stained using $3 \%$ fuchsin and the dental surfaces of some teeth were classified according to the amount of dental biofilm. The children were asked to maintain fasting and avoid oral hygiene for a minimum of $2 \mathrm{~h}$ prior to the examination.

After dental cleaning with rotating bristle brush and pumice/water slurry, the teeth were assessed regarding dental erosion. We used the O'Brien index [18] to assess the presence of dental erosion. In addition, the children were asked whether they have experienced a bitter taste in their mouth.

A face-to-face interview was performed with the caregivers, who answered a questionnaire concerning their children's dietary habits. The questionnaire detailed the consumption and frequency of foods considered erosive, such as citrus fruits, fruit juices, carbonated soft drinks, tea, and acidic candies. The parents were also asked about certain habits concerning soft drink consumption, such as the temperature of the beverage and drinking methods (use of a straw, swallowing immediately, or holding the beverage in the mouth before swallowing).

2.3. Diagnosis of $D H$. The presence of dentine hypersensitivity was determined by a single examiner trained to diagnose the problem, according to the criteria proposed by Porto et al. [6]. The examiner performed a detailed clinical history and dental examination in order to eliminate possible causes of pain, which permitted the differentiation of dentine hypersensitivity from other dental pathologies. The air jet from a triple syringe was used on surfaces of the teeth to provoke a response from the patient and identify areas with suspected dentin hypersensitivity [6].

2.4. Salivary Collection. At least $2 \mathrm{~h}$ after the previous meal and after being oriented not to brush the teeth, stimulated whole saliva with Parafilm was collected between 8 and 10 a.m., to minimize the circadian rhythm effects. Saliva produced in the first $10 \mathrm{~s}$ was discarded and the subsequent saliva was collected for exactly $5 \mathrm{~min}$ in a graduated cylinder to calculate the initial flow rate $(\mathrm{mL} / \mathrm{min})$. During the collection period, all individuals remained comfortably seated in a ventilated and illuminated room/environment. Soon after collection, a part of salivary sample was frozen in dry ice, transported to the laboratory, and stored at $-80^{\circ} \mathrm{C}$ until analysis.

Immediately after saliva collection, both initial $\mathrm{pH}$ and buffer capacity were determined using a portable $\mathrm{pH}$ meter (Digimed DU-2, Sao Paulo, Brazil). The salivary buffer capacity of whole saliva was determined by acid titration of $1 \mathrm{~mL}$ of saliva with a constant amount of $0.01 \mathrm{~N} \mathrm{HCl}(0.2 \mathrm{~mL})$. After each addition of acid, the change in $\mathrm{pH}$ was monitored until the saliva-acid solution reached $\mathrm{pH}$ 5.0. For interpretation of the results regarding $\mathrm{pH}$ changes, the buffer capacity of whole saliva was analyzed using $\mathrm{pH}$ intervals (initial $\mathrm{pH}-7.0$; pH 6.9-6.0; pH 5.9-5.0). For practical purposes, the salivary buffer capacity was expressed as the volume $(\mathrm{mL})$ of the acid added to $1 \mathrm{~mL}$ of saliva.

2.5. Biochemical Analysis. Calcium concentration was performed by method described by Nogueira et al. [19]. Salivary calcium is precipitated by chloranilic acid, in the form of calcium chloranilate. After washing in isopropyl alcohol $50 \%$, the precipitate is dissolved in an aqueous solution of $5 \%$ EDTA (ethylenediaminetetraacetic acid). Calcium phosphate $(0.1 \mathrm{mg} / \mathrm{mL})$ is used as a standard solution and the result is determined by reading in a spectrophotometer at $520 \mathrm{~nm}$.

The concentration of phosphorus in the saliva was determined by the modified method of Fiske and Subbarow [20]. Saliva is deproteinized by incubation with TCA (trichloroacetic acid) 1.2 M. Once deproteinized, the phosphate minerals react with molybdic acid (solution of $2.5 \%$ ammonium molybdate in $10 \mathrm{~N}$ sulfuric acid) to form a complex of phosphomolybdic acid, which is then reduced by ascorbic acid to form a blue colored complex in which the color intensity is proportional to the amount of inorganic phosphorus. The standard curve is determined by reaction 
TABle 1: Univariate Poisson regression analysis of possible factors related to the child associated with dental hypersensitivity.

\begin{tabular}{|c|c|c|c|c|}
\hline Independent variables & Total $N$ & $\begin{array}{c}\text { Children with } \mathrm{DH} \\
\qquad N(\%) \\
\end{array}$ & $\begin{array}{c}\mathrm{PR} \\
(95 \% \mathrm{CI}) \\
\end{array}$ & $P^{*}$ \\
\hline Age (cont.) & & & $\begin{array}{c}0.97 \\
(0.78 \text { to } 1.19)\end{array}$ & 0.784 \\
\hline \multicolumn{5}{|l|}{ Sex } \\
\hline (ref.: male) & 26 & $11(42.3)$ & 1.00 & \multirow{2}{*}{0.923} \\
\hline Female & 22 & $9(40.9)$ & $\begin{array}{c}0.97 \\
(0.49 \text { to } 1.91)\end{array}$ & \\
\hline \multicolumn{5}{|l|}{ Dental erosion } \\
\hline (ref.: absent) & 24 & $6(25.0)$ & 1.00 & \multirow{2}{*}{0.033} \\
\hline Present & 24 & $14(58.3)$ & $\begin{array}{c}2.33 \\
(1.07 \text { to } 5.09)\end{array}$ & \\
\hline \multicolumn{5}{|l|}{ Bitter taste } \\
\hline (ref.: no) & 39 & $13(33.3)$ & 1.00 & \multirow{2}{*}{0.004} \\
\hline Yes & 9 & $7(77.8)$ & $\begin{array}{c}2.33 \\
(1.32 \text { to } 4.13)\end{array}$ & \\
\hline \multicolumn{5}{|l|}{ Temperature of soft drink } \\
\hline (ref.: room temperature) & 19 & $9(47.4)$ & 1.00 & \multirow[t]{2}{*}{0.517} \\
\hline Cold/iced & 29 & $11(37.9)$ & $\begin{array}{c}0.80 \\
(0.41 \text { to } 1.57)\end{array}$ & \\
\hline \multicolumn{5}{|l|}{ Usual drinking method } \\
\hline (ref.: Swallowing immediately) & 39 & $14(35.9)$ & 1.00 & \multirow{2}{*}{0.054} \\
\hline Holding the beverage in the mouth before swallowing & 9 & $6(66.7)$ & $\begin{array}{c}1.86 \\
(0.99 \text { to } 3.49)\end{array}$ & \\
\hline Simplified Oral Hygiene Index (cont.) & & & $\begin{array}{c}0.47 \\
(0.24 \text { to } 0.94)\end{array}$ & 0.033 \\
\hline
\end{tabular}

$\mathrm{DH}=$ dental hypersensitivity; $\mathrm{PR}=$ prevalence ratio; $95 \% \mathrm{CI}=95 \%$ confidence interval.

${ }^{*}$ Calculated by the Wald test.

with a $1 \mathrm{Mmol} / \mathrm{mL}$ standard phosphorus solution and by spectrophotometry at $720 \mathrm{~nm}$.

2.6. Statistical Analyses. For the analysis, each child was the experimental unit and DH was considered the outcome. The independent variables were as follows: sex, male or female; age, a continuous variable in years; dental erosion, absent or present; bitter taste, no or yes; temperature of soft drink, room temperature versus cold or iced drink; usual drinking method, by swallowing immediately or using straw versus holding the beverage in the mouth before swallowing; and OHI-S, a continuous variable. The independent variables related to dietary habits consumption were as follows: soft drinks intake, some days versus every day; juice intake, 3 times per day or less versus more than 3 times/day; tea intake, never or rarely versus once a week or more; citrus fruits intake, never or rarely versus once a week or more; and acidic candies intake, never or rarely versus once a week or more. The salivary parameters investigated were salivary flow rate, calcium and phosphorus concentration, initial $\mathrm{pH}$, and buffer capacity (in each $\mathrm{pH}$ range and total).

The analyses were performed through Poisson regression with robust variance. First, univariate analyses were performed with each independent variable alone. The prevalence ratio (PR) values and 95\% confidence intervals (95\% CI) were calculated. The variables which achieved a $P$ value $<0.20$ in the univariate analyses were tested in the multiple model using a forward stepwise procedure. Following multiple Poisson regression analysis, only variables with a $P$ value $<$ 0.05 were maintained in the final model.

\section{Results}

A total of 48 children participated in this study and of these, $20(41 \%)$ presented $\mathrm{DH}$ and $28(59 \%)$ presented no DH. The mean (standard deviation) age of the $\mathrm{DH}$ group was 6.72 (1.64) years old and the control group (with no DH) was 6.93 (1.61) years old. The sample comprised 26 males (54.2\%) and 22 females $(45.8 \%)$.

In the univariate analysis, we observed that children presenting signs of dental erosion showed higher prevalence of $\mathrm{DH}$ than children with no dental erosion. Children that reported a bitter taste also presented higher prevalence of DH (Table 1). Concerning dietary habits, no dietary habit was significantly associated with higher prevalence of $\mathrm{DH}$ (Table 2).

Considering the salivary parameters, children presenting higher salivary flow rate exhibited higher prevalence of $\mathrm{DH}$. Other salivary parameters, however, showed no significant association with DH (Table 3). 
TABLE 2: Univariate Poisson regression analysis of the association between children's dietary habits and presence of dental hypersensitivity.

\begin{tabular}{|c|c|c|c|c|}
\hline Dietary habits variables & Total $N$ & $\begin{array}{c}\text { Children with } \mathrm{DH} \\
\mathrm{N}(\%) \\
\end{array}$ & $\begin{array}{c}\text { PR } \\
(95 \% \mathrm{CI}) \\
\end{array}$ & $P^{*}$ \\
\hline \multicolumn{5}{|l|}{ Soft drinks intake } \\
\hline (ref.: some days) & 27 & $9(33.3)$ & 1.00 & \multirow{2}{*}{0.192} \\
\hline Everyday & 21 & $11(52.4)$ & $\begin{array}{c}1.57 \\
(0.79 \text { to } 3.10)\end{array}$ & \\
\hline \multicolumn{5}{|l|}{ Juice intake } \\
\hline (ref.: 3 times/day or less) & 24 & $9(37.5)$ & 1.00 & \multirow{2}{*}{0.564} \\
\hline More than 3 times/day & 24 & $11(45.8)$ & $\begin{array}{c}1.22 \\
(0.62 \text { to } 2.42)\end{array}$ & \\
\hline \multicolumn{5}{|l|}{ Tea intake } \\
\hline (ref.: never/rarely) & 35 & $13(37.1)$ & 1.00 & \multirow[t]{2}{*}{0.277} \\
\hline Once a week or more & 13 & $7(53.8)$ & $\begin{array}{c}1.45 \\
(0.74 \text { to } 2.83)\end{array}$ & \\
\hline \multicolumn{5}{|l|}{ Citrus fruits intake } \\
\hline (ref.: never/rarely) & 32 & $13(40.6)$ & 1.00 & \multirow[t]{2}{*}{0.836} \\
\hline Once a week or more & 16 & $7(43.8)$ & $\begin{array}{c}1.08 \\
(0.53 \text { to } 2.18)\end{array}$ & \\
\hline \multicolumn{5}{|l|}{ Acidic candies intake } \\
\hline (ref.: never/rarely) & 8 & $1(12.5)$ & 1.00 & \multirow{2}{*}{0.164} \\
\hline Once a week or more & 40 & $19(47.5)$ & $\begin{array}{c}3.80 \\
(0.58 \text { to } 24.95)\end{array}$ & \\
\hline
\end{tabular}

$\mathrm{DH}=$ dental hypersensitivity; $\mathrm{PR}=$ prevalence ratio; $95 \% \mathrm{CI}=95 \%$ confidence interval.

* Calculated by the Wald test.

TABLE 3: Univariate Poisson regression analysis between salivary parameters and presence of dental hypersensitivity.

\begin{tabular}{|c|c|c|c|c|}
\hline Salivary parameters & $\begin{array}{c}\text { Without DH } \\
\text { mean }(\mathrm{SD})\end{array}$ & $\begin{array}{l}\text { With DH } \\
\text { mean (SD) }\end{array}$ & $\begin{array}{c}\mathrm{PR} \\
(95 \% \mathrm{CI})\end{array}$ & $P^{*}$ \\
\hline Salivary flow rate $(\mathrm{mL} / \mathrm{min})$ & $0.49(0.27)$ & $0.66(0.31)$ & $\begin{array}{c}2.56 \\
(1.28 \text { to } 5.12)\end{array}$ & 0.008 \\
\hline Calcium concentration $(\mu \mathrm{g} / \mathrm{mL})$ & $194.9(61.6)$ & $182.1(40.8)$ & $\begin{array}{c}1.00 \\
(0.99 \text { to } 1.01)\end{array}$ & 0.404 \\
\hline Phosphate concentration $(\mathrm{mg} / \mathrm{mL})$ & $1.16(0.33)$ & $1.16(0.25)$ & $\begin{array}{c}1.01 \\
(0.33 \text { to } 3.07)\end{array}$ & 0.988 \\
\hline Initial $\mathrm{pH}$ & $7.42(0.28)$ & $7.45(0.36)$ & $\begin{array}{c}1.23 \\
(0.39 \text { to } 3.89)\end{array}$ & 0.725 \\
\hline $\begin{array}{l}\text { Total buffer capacity } \\
(\mathrm{mL} \mathrm{HCl} 0.01 \mathrm{~N})\end{array}$ & $1.31(0.31)$ & $1.33(0.39)$ & $\begin{array}{c}1.08 \\
(0.39 \text { to } 3.03)\end{array}$ & 0.879 \\
\hline \multicolumn{5}{|l|}{$\begin{array}{l}\text { Buffer capacity in each pH range } \\
(\mathrm{mL} \mathrm{HCl} 0.01 \mathrm{~N})\end{array}$} \\
\hline pHi-7.0 & $0.34(0.24)$ & $0.32(0.24)$ & $\begin{array}{c}0.84 \\
(0.18 \text { to } 3.87)\end{array}$ & 0.827 \\
\hline $6.9-6.0$ & $0.60(0.19)$ & $0.63(0.27)$ & $\begin{array}{c}1.42 \\
(0.31 \text { to } 6.52)\end{array}$ & 0.836 \\
\hline $5.9-5.0$ & $0.38(0.10)$ & $0.38(0.09)$ & $\begin{array}{c}1.10 \\
(0.03 \text { to } 38.86)\end{array}$ & 0.958 \\
\hline
\end{tabular}

$\mathrm{DH}=$ dental hypersensitivity; $\mathrm{PR}=$ prevalence ratio; $95 \% \mathrm{CI}=95 \%$ confidence interval; $\mathrm{SD}=$ standard deviation.

* Calculated by the Wald test.

In the multiple Poisson regression analysis, we obtained a multiple model containing two variables as follows: salivary flow rate and presence of dental erosion. In this model, children exhibiting dental erosion presented twice the $\mathrm{DH}$, and children with higher salivary flow rate also presented higher prevalence of $\mathrm{DH}$ (Table 4, model 1). When we tested other variables, such as bitter taste and OHI-S together with dental erosion, most of the variables lost their significance. Thus, we decided to construct other multiple models without dental erosion. In the second multiple regression model, we 
TABLE 4: Multiple Poisson regression analysis between independent variables and presence of dental hypersensitivity.

\begin{tabular}{lcc}
\hline Salivary parameters & $\begin{array}{l}\text { Adjusted prevalence ratio } \\
(95 \% \text { confidence interval })\end{array}$ & $P^{*}$ \\
\hline Final multiple model 1 & $2.49(1.05$ to 5.91$)$ & \\
$\quad$ Salivary flow $(\mathrm{mL} / \mathrm{min})$ & $2.23(1.05$ to 4.71$)$ & \\
$\quad$ Presence of dental erosion & & $<0.001$ \\
Final multiple model 2 & $2.88(1.58$ to 5.25$)$ & \\
$\quad$ Salivary flow (mL/min) & $2.36(1.38$ to 4.02$)$ & \\
$\quad$ Bitter taste & $0.47(0.23$ to 0.97$)$ & \\
Simplified Oral Hygiene Index &
\end{tabular}

${ }^{*} P$ value of the final model.

observed that children with bitter taste in their mouth and with higher salivary flow rate presented higher prevalence of DH. In contrast, children exhibiting higher levels of OHI-S presented lower prevalence of DH (Table 4, final model 2).

\section{Discussion}

Knowledge of etiologic factors of a disease or symptoms is of fundamental importance for the definition of preventive and therapeutic measures. This study evaluated clinical and salivary factors that could be involved in the etiology of DH in children. This condition has not been extensively studied in children, and most studies have reported association with developmental defects of enamel $[15,16]$. In our study, we observed association with factors related to dental erosion. Furthermore, we observed that children with DH presented an increased salivary flow rate in stimulated whole saliva compared with children without any complaints. To our knowledge, this is the first study that has investigated the association of salivary parameters with $\mathrm{DH}$ in children.

The most important finding of our study is that higher prevalence of $\mathrm{DH}$ was determined in children with factors related to dental erosion. Some similarity exists between the etiology of dental erosion and DH [21]. Dentine hypersensitivity is associated with dentine exposed to the oral environment while dental erosion was defined by Pindborg [22] as the superficial loss of hard tissues of the teeth by a chemical process that does not involve bacterial action. The action of common etiologic factors can explain this association.

When we included dental erosion in the final multiple model, a sense of bitter taste and the presence of dental biofilm lost their significance. The loss of significance of dental biofilm could be due to colinearity with dental erosion, since some authors have reported a protective effect of dental biofilm against dental erosion [23]. Furthermore, acids responsible for the etiology of dental erosion can be of intrinsic origin, which includes gastrointestinal disorders, gastroesophageal disease, anorexia, and bulimia, in which regurgitation and frequent vomiting are common [24]. Although the investigation of intrinsic factors of erosive lesions was not the focus of our study, the children reported frequently sensing a bitter taste, which was associated with $\mathrm{DH}$. The bitter taste could be indicative of the participation of intrinsic factors in $\mathrm{DH}$, a fact that requires corroboration by future studies.

Another interesting finding was the significant negative association between dental biofilm and DH. This finding is in agreement with previous studies that showed the protective effect of dental biofilm in cases of DH $[13,23]$. The acquired enamel pellicle and dental biofilm are a natural protection of mineralized surface against erosion or abrasion, preventing the output of calcium and phosphate from the liquid phase of hydroxyapatite and direct contact by acid on the tooth surface, acting as a selective barrier of ions [25]. Stimulation of natural defense factors could have preventive and therapeutic potential in the treatment of $\mathrm{DH}$ and could prove to be a subject of interest in medical science, considering that the occlusion of dentinal tubules and surface protection are one of the first approaches in the treatment of $\mathrm{DH}$ resulting in sealed tubules and isolation from external stimuli $[6,26-28]$.

Confirmation of the association between factors related to dental erosion and $\mathrm{DH}$ was obtained in the alternative final multiple model that we constructed. Following the exclusion of the presence of dental erosion, both bitter taste and OHI$S$ variables were significantly associated with $\mathrm{DH}$ in the final model.

Lifestyle has changed over the years and the current consumption of acidic foods and beverages is extremely high, especially among children $[24,29,30]$. The acidic components are common in modern eating habits, particularly from fruits [31]. Chemical stimulus is one of the factors responsible for dentine hypersensitivity, which generates great physical and psychological discomfort for patients [6]. Although an acidic diet has been related to DH in some studies [30, 3234], our results showed no association between DH and the frequency or manner of intake of erosive foods and drinks.

Although saliva plays an essential role in maintaining the integrity of mineralized tissues of the tooth, no previous reports have considered their importance in cases of $\mathrm{DH}$. The only salivary factor positively associated with $\mathrm{DH}$ was the salivary flow rate. The stimulation of salivary flow can enhance the defense functions performed by saliva, such as mechanical cleaning, antimicrobial properties, mucosal lubrication, clearance of food residues, and buffer capacity [11]. It is possible that the salivary flow rate could be stimulated by the same factor that causes the bitter taste often reported by the children with $\mathrm{DH}$. For this reason, it would be interesting to develop studies that address gastrointestinal problems or intrinsic factors of dental erosion and their possible correlations with $\mathrm{DH}$.

Despite its important contribution concerning the clinical and salivary elements on the etiology of $\mathrm{DH}$, some limitations to the study should be mentioned. Diagnosis of $\mathrm{DH}$ in individuals in the age range of group studied should be conducted very carefully, because children can show difficulty in verbalizing and can be induced to error of complaint by suggestion of pain. Furthermore, we selected a convenience sample with children presenting dental erosion and counterparts without erosion. The small sample size is also a limiting factor. Notwithstanding these limitations, this pioneer study 
opens new avenues that should assist in improving current understanding concerning DH in children.

\section{Conclusion}

In conclusion, increased salivary flow rate and factors related to the presence of dental erosion are associated with the occurrence of $\mathrm{DH}$ in children.

This study provides important elements that will help the pediatric dentist to understand the $\mathrm{DH}$ in children. Furthermore, these results may be an alert because probably intrinsic factors of dental erosion which cause the bitter taste and salivary stimulation are associated with $\mathrm{DH}$ in children. The intrinsic factors of dental erosion need to be carefully investigated.

\section{Disclaimer}

The authors alone are responsible for the content and writing of the paper.

\section{Conflict of Interests}

The authors Caleb Shitsuka, Fausto Medeiros Mendes, Maria Salete Nahás Pires Corrêa, and Mariana Ferreira Leite report no conflict of interests. The authors certify that they do not have any commercial or associate interest that represents conflict of interests in connection with the submitted paper.

\section{Acknowledgments}

The authors would like to thank the CAPES, FAPESP, and the participants of the Post-Graduation in Paediatric Dentistry Seminar of FOUSP for the critical comments put forth.

\section{References}

[1] R. H. Dababneh, A. T. Khouri, and M. Addy, "Dentine hypersensitivity-an enigma? A review of terminology, epidemiology, mechanisms, aetiology and management," British Dental Journal, vol. 187, no. 11, pp. 606-611, 1999.

[2] D. G. Gillam, A. Aris, J. S. Bulman, H. N. Newman, and F. Ley, "Dentine hypersensitivity in subjects recruited for clinical trials: clinical evaluation, prevalence and intra-oral distribution," Journal of Oral Rehabilitation, vol. 29, no. 3, pp. 226-231, 2002.

[3] S. R. Samuel, S. G. Khatri, and S. Acharya, "Clinical evaluation of self and professionally applied desensitizing agents in relieving dentinhypersensitivity after a single topical application: a randomized controlled trial," Journal of Clinical and Experimental Dentistry, vol. 6, no. 4, pp. e339-e343, 2014.

[4] G. R. Holland, M. N. Narhi, M. Addy, L. Gangarosa, and R. Orchardson, "Guidelines for the design and conduct of clinical trials on dentine hypersensitivity," Journal of Clinical Periodontology, vol. 24, no. 11, pp. 808-813, 1997.

[5] M. Brännström, L. A. Lindén, and A. Aström, "The hydrodynamics of the dental tubule and of pulp fluid. A discussion of its significance in relation to dentinal sensitivity," Caries Research, vol. 1, no. 4, pp. 310-317, 1967.
[6] I. C. C. M. Porto, A. K. M. Andrade, and M. A. J. R. Montes, "Diagnosis and treatment of dentinal hypersensitivity," Journal of Oral Science, vol. 51, no. 3, pp. 323-332, 2009.

[7] C. H. Splieth and A. Tachou, "Epidemiology of dentin hypersensitivity," Clinical Oral Investigations, vol. 17, supplement 1, pp. 3-8, 2013.

[8] G. M. Naidu, K. C. Ram, N. R. Sirisha et al., "Prevalence of dentin hypersensitivity and related factors among adult patients visiting a dental school in andhra pradesh, southern India," Journal of Clinical and Diagnostic Research, vol. 8, no. 9, pp. 4851, 2014.

[9] T. Scaramucci, T. E. de Almeida Anfe, S. da Silva Ferreira, A. C. Frias, and M. A. P. Sobral, "Investigation of the prevalence, clinical features, and risk factors of dentin hypersensitivity in a selected Brazilian population," Clinical Oral Investigations, vol. 18, no. 2, pp. 651-657, 2014.

[10] M. Addy and N. Pearce, "Aetiological, predisposing and environmental factors in dentine hypersensitivity," Archives of Oral Biology, vol. 39, supplement, pp. S33-S38, 1994.

[11] P. D. V. de Almeida, A. M. T. Grégio, M. Â. N. Machado, A. A. S. de Lima, and L. R. Azevedo, "Saliva composition and functions: a comprehensive review," Journal of Contemporary Dental Practice, vol. 9, no. 3, pp. 72-80, 2008.

[12] F. García-Godoy and M. J. Hicks, "Maintaining the integrity of the enamel surface: the role of dental biofilm, saliva and preventive agents in enamel demineralization and remineralization," Journal of the American Dental Association, vol. 139, no. 5, pp. 25S-34S, 2008.

[13] M. Addy, P. Mostafa, and R. G. Newcombe, "Dentine hypersensitivity: the distribution of recession, sensitivity and plaque," Journal of Dentistry, vol. 15, no. 6, pp. 242-248, 1987.

[14] M. S. Wolff, "Dentin hypersensitivity, the biofilm and remineralization: what is the connection?" Advances in Dental Research, vol. 21, no. 1, pp. 21-24, 2009.

[15] C. M. de Souza-e-Silva, T. M. Parisotto, C. Steiner-Oliveira, M. B. D. Gavião, and M. Nobre-dos-Santos, "Oral rehabilitation of primary dentition affected by amelogenesis imperfecta: a case report," Journal of Contemporary Dental Practice, vol. 11, no. 3, pp. 71-77, 2010.

[16] N. A. Lygidakis, A. Chaliasou, and G. Siounas, "Evaluation of composite restorations in hypomineralised permanent molars: a four year clinical study," European Journal of Paediatric Dentistry, vol. 4, pp. 143-148, 2003.

[17] J. C. Greene and J. R. Vermillion, "The simplified oral hygiene index," Journal of the American Dental Association, vol. 68, pp. 7-13, 1964.

[18] M. O'Brien, Children's Dental Health in the United Kingdom, 1993, Office of Population Censuses and Surveys, Her Majesty's Stationery Office, London, UK, 1994.

[19] F. N. Nogueira, D. N. Souza, and J. Nicolau, "In vitro approach to evaluate potential harmful effects of beer on teeth," Journal of Dentistry, vol. 28, no. 4, pp. 271-276, 2000.

[20] C. H. Fiske and Y. Subbarow, "The colorimetric determination of phosphorus," The Journal of Biological Chemistry, vol. 66, pp. 375-400, 1925.

[21] D. T. Zero and A. Lussi, "Erosion: chemical and biological factors of importance to the dental practitioner," International Dental Journal, vol. 55, no. 4, pp. 285-290, 2005.

[22] J. J. Pindborg, Pathology of Dental Hard Tissues, Munsksgaard, Copenhagen, Denmark, 1970. 
[23] A. Cheung, Z. Zid, D. Hunt, and J. McIntyre, "The potential for dental plaque to protect against erosion using an in vivo-in vitro model-a pilot study," Australian Dental Journal, vol. 50, no. 4, pp. 228-234, 2005.

[24] A. Lussi, E. Hellwig, D. Zero, and T. Jaeggi, "Erosive tooth wear: diagnosis, risk factors and prevention," The American Journal of Dentistry, vol. 19, no. 6, pp. 319-325, 2006.

[25] M. J. Larsen and G. Ravnholt, "Dissolution of various calcium fluoride preparations in inorganic solutions and in stimulated human saliva," Caries Research, vol. 28, no. 6, pp. 447-454, 1994.

[26] V. Camilotti, J. Zilly, P. do Monte Ribeiro Busato, C. A. Nassar, and P. O. Nassar, "Desensitizing treatments for dentin hypersensitivity: a randomized, split-mouth clinical trial," Brazilian Oral Research, vol. 26, no. 3, pp. 263-268, 2012.

[27] A. Guentsch, K. Seidler, S. Nietzsche et al., "Biomimetic mineralization: long-term observations in patients with dentin sensitivity," Dental Materials, vol. 28, no. 4, pp. 457-464, 2012.

[28] R. Umberto, R. Claudia, P. Gaspare, T. Gianluca, and D. V. Alessandro, "Treatment of dentine hypersensitivity by diode laser: a clinical study," International Journal of Dentistry, vol. 2012, Article ID 858950, 8 pages, 2012.

[29] A. Lussi, N. Schlueter, E. Rakhmatullina, and C. Ganss, "Dental erosion-an overview with emphasis on chemical and histopathological aspects," Caries Research, vol. 45, no. 1, pp. 2 $12,2011$.

[30] M. S. N. P. Corrêa, F. N. P. Corrêa, J. P. N. P. Corrêa, C. Murakami, and F. M. Mendes, "Prevalence and associated factors of dental erosion in children and adolescents of a private dental practice," International Journal of Paediatric Dentistry, vol. 21, no. 6, pp. 451-458, 2011.

[31] D. W. Bartlett, "The role of erosion in tooth wear: aetiology, prevention and management," International Dental Journal, vol. 55, no. 4, pp. 277-284, 2005.

[32] D. C. Clark, G. Woo, J. G. Silver, D. Sweet, and J. C. Grisdale, "The influence of frequent ingestion of acids in the diet on treatment for dentin sensitivity," Journal Canadian Dental Association, vol. 56, no. 12, pp. 1101-1103, 1990.

[33] F. O. B. Corrêa, J. E. C. Sampaio, C. Rossa Jr., and S. R. P. Orrico, "Influence of natural fruit juices in removing the smear layer from root surfaces-an in vitro study," Journal of the Canadian Dental Association, vol. 70, no. 10, pp. 697-702, 2004.

[34] D. W. Bartlett, J. Fares, S. Shirodaria, K. Chiu, N. Ahmad, and M. Sherriff, "The association of tooth wear, diet and dietary habits in adults aged 18-30 years old," Journal of Dentistry, vol. 39, no. 12, pp. 811-816, 2011. 


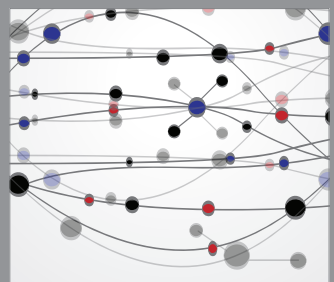

The Scientific World Journal
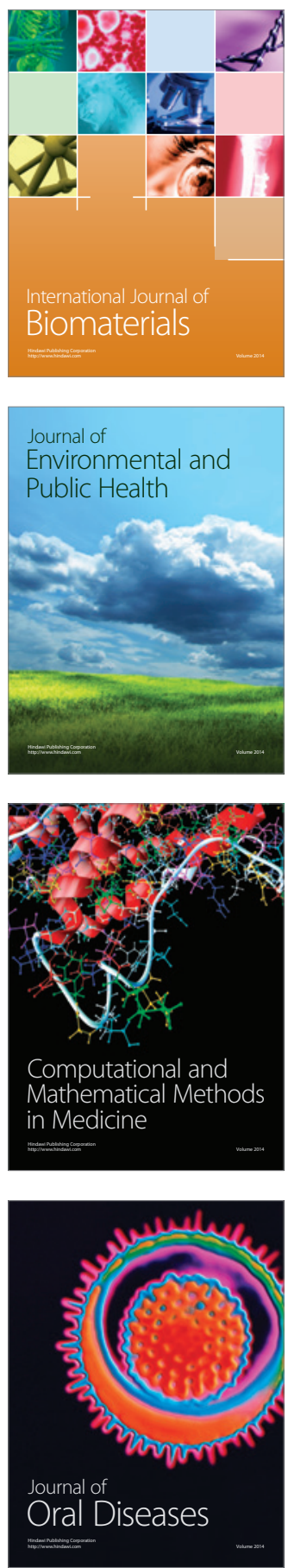
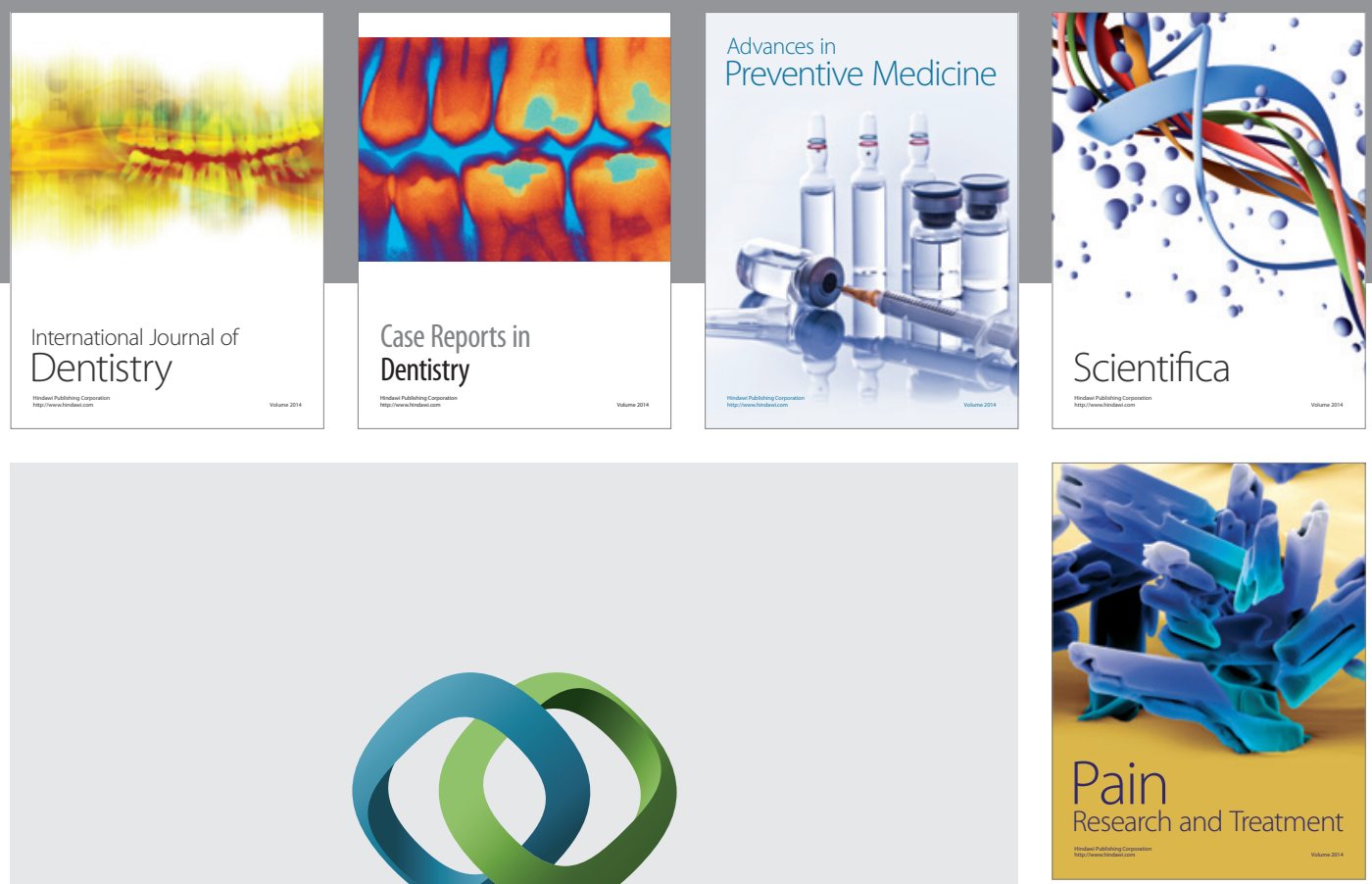

\section{Hindawi}

Submit your manuscripts at

http://www.hindawi.com
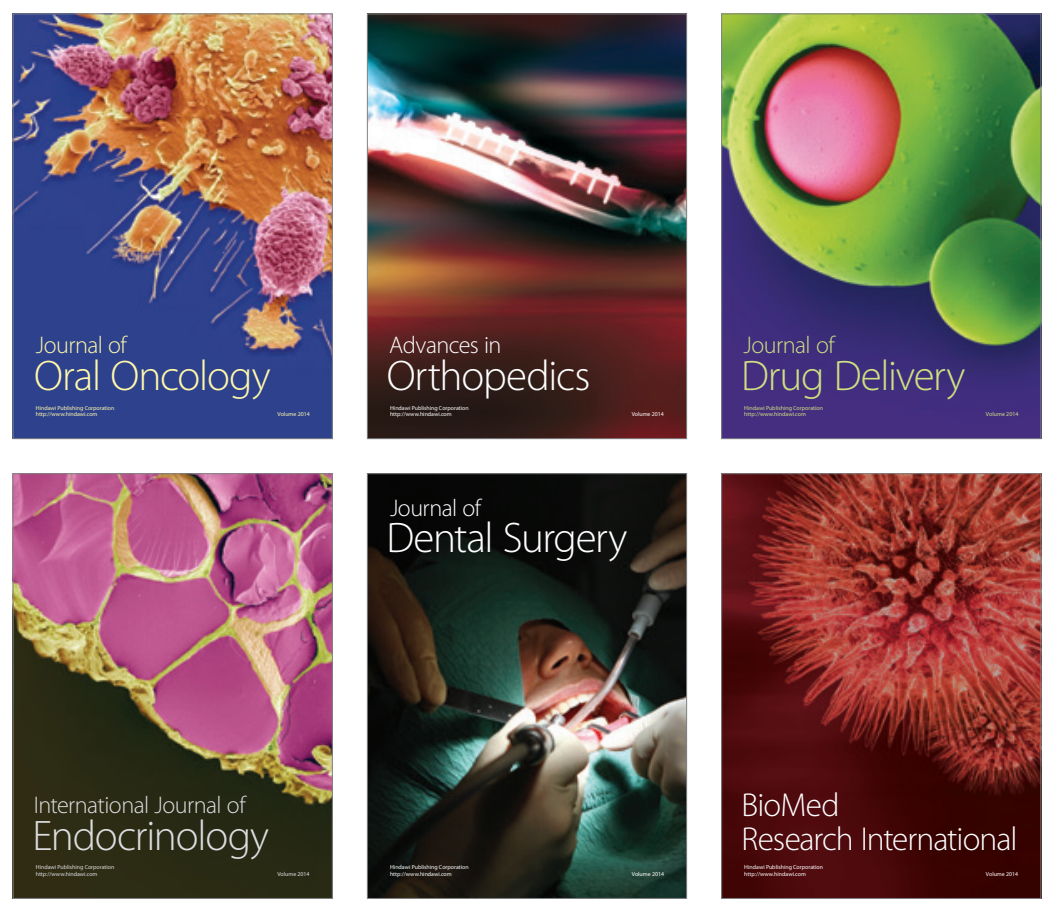

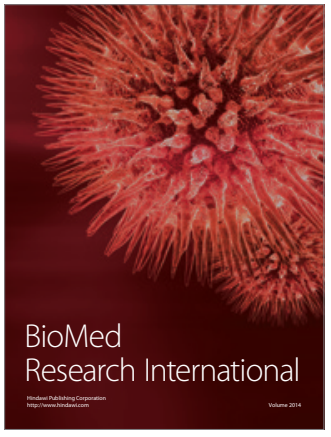

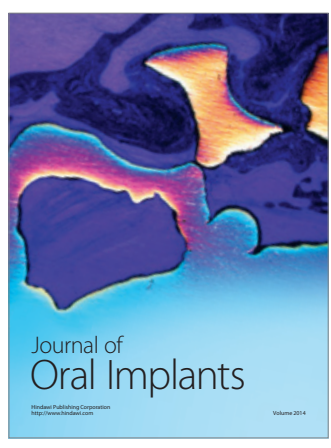
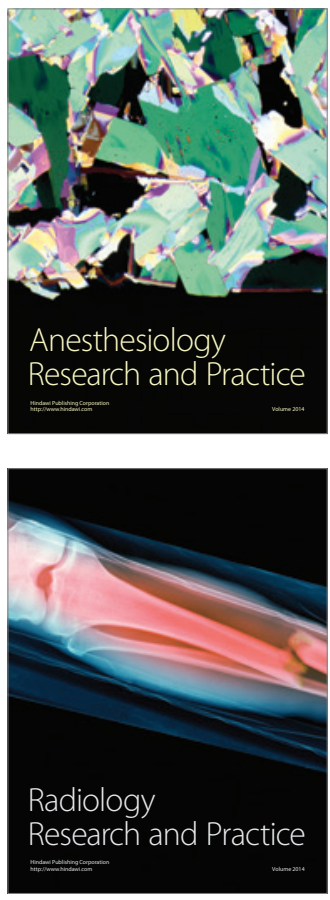